\title{
PENERAPAN THE DUDE SEBAGAI SISTEM MONITORING DENGAN NOTIFIKASI OTOMATIS MELALUI EMAIL, TELEGRAM DAN SMS
}

\author{
Moch Khaidar Elhaq, Arip Solehudin, Didi Juardi \\ Universitas Singaperbangsa Karawang (UNSIKA) Jawa Barat, Indonesia \\ Email: moch.khaidar17133@student.unsika.ac.id, arip.solehudin@gmail.com, \\ didi.juardi@staff.unsika.ac.id
}

\begin{abstract}
Abstrak
Tujuan dilakukan penelitian ini karena adanya masalah pada administrator jaringan HE.Net Perumnas Karawang yang mengalami kesulitan untuk mengetahui perangkat mana yang bermasalah atau mati secara tiba-tiba. Sehingga dibutuhkan The Dude sebagai sistem monitoring jaringan agar dapat dikontrol dan dikelola serta memastikan pengoperasian jaringan tersebut normal. Penelitian ini dilakukan dengan menggunakan metode Network Design Life Cycle (NDLC). Hasil penelitian yang telah dilakukan dapat disimpulkan bahwa ketika terjadi perubahan status device, notifikasi dapat terkirim melalui email, telegram dan SMS. Informasi pada ketiga notifikasi tersebut berisi Ip address dan status device, serta waktu dan tanggal perubahan status device yang terkirim sesuai dengan yang ada pada the dude dan mikrotik. Pengujian dilakukan 4 kali, baik pada email, telegram dan sms dengan persentase keberhasilan $100 \%$. Hasil perbandingan antara jumlah kejadian dipresentasekan dengan nilai maksimal presentase sebesar $100 \%$, maka didapat nilai error $0 \%$ dengan rata rata pengiriman melalui email 8,75 detik, telegram 3,5 detik dan 13,5 detik untuk SMS.
\end{abstract}

Kata Kunci: monitoring jaringan; the dude; email; telegram; SMS

\section{Abstract}

The purpose of this research was due to a problem with the network administrator of HE.Net Perumnas Karawang who had difficulty knowing which device was problematic or died suddenly. So it takes The Dude as a network monitoring system in order to be controlled and managed and ensure the operation of the network is normal. This research was conducted using Network Design Life Cycle (NDLC) method. The results of the research that has been done can be concluded that when there is a change in the status of the device, notifications can be sent via email, telegram and SMS. The information on the three notifications contains ip address and device status, as well as the time and date of the device status change sent in accordance with the dude and mikrotik. The test was conducted 4 times, both on email, telegram and sms with a $100 \%$ success percentage. The result of the comparison between the number of events is percentage with a maximum percentage value of $100 \%$, then obtained an error value of $0 \%$ with an average email delivery of 8.75 seconds, telegram 3.5 seconds and 13.5 seconds for SMS.

How to cite:

E-ISSN:

Published by:
Elhaq, Moch Khaidar., Arip Solehudin, Didi Juardi (2021) Penerapan The Dude Sebagai Sistem Monitoring Dengan Notifikasi Otomatis Melalui Email, Telegram dan SMS. Syntax Literate: Jurnal Ilmiah Indonesia. 6(7). http://dx.doi.org/10.36418/syntax-literate.v6i7.3640 2548-1398

Ridwan Institute 
Keywords: network monitoring; the dude; email, telegram; SMS

\section{Pendahuluan}

Di era modern ini, internet sangat berkontribusi penting dalam kehidupan masyarakat. Dimana internet menjadi sumber informasi yang selalu digunakan baik di rumah, instansi, maupun industri. Keperluan penerapan jaringan komputer terus mengalami kenaikan menjadikan sistem jaringan yang terpasang menjadi rumit. Meningkatnya risiko gangguan jaringan komputer, sehingga perlunya pemasangan sistem monitoring jaringan agar jaringan dapat dikontrol dan dikelola serta pastikan pengoperasian jaringan tersebut normal (Idrus, 2016).

Menurut (Farida, 2016) menjelaskan bahwa pemantauan jaringan merupakan proses rutin kegiatan pengumpulan data dan kemajuan jaringan komputer, proses ini memantau setiap perubahan yang terjadi untuk melindungi manajemen jaringan yang ada dan menentukan apakah peralatan yang terhubung ke jaringan komputer beroperasi secara normal. Jika salah satu perangkat yang digunakan menghasilkan interferensi, maka akan mengurangi fungsionalitas dari infrastruktur jaringan. Hal ini membutuhkan solusi efektif yang dapat memantau layanan atau interupsi dari setiap node tertentu dalam infrastruktur jaringan sehingga administrator jaringan dapat dengan cepat menyelesaikannya. (Rinaldo, 2016) menjelaskan bahwa dengan menggunakan perangkat router Mikrotik, monitoring jaringan dapat dilakukan dengan aplikasi the dude yang dibuat oleh Mikrotik. The dude merupakan aplikasi yang cukup andal dalam memonitoring sistem jaringan komputer serta mendukung pemberitahuan. Penelitian lainya yang dilakukan oleh (Sutarti \& Alfiyansyah, 2017) menjelaskan bahwa hasil penelitian tersebut adalah penerapan mikrotik $O S$ dan the dude sebagai monitoring jaringan di tempat tersebut dapat diimplementasikan sehingga lebih dini dalam mendeteksi masalah atau gangguan jaringan dan mempermudah dalam penyelesaian.

Berdasarkan latar belakang, penelitian ini akan membahas "Penerapan The Dude Sebagai Sistem Monitoring Dengan Notifikasi Otomatis Melalui Email, Telegram dan SMS" maka dengan adanya pembahasan ini dapat memudahkan kinerja seorang administrator jaringan. Tujuan dari penelitian ini adalah untuk mengimplementasikan monitoring jaringan dengan menggunakan the dude serta sebagai sistem monitoring dan manajemen perangkat pada pengiriman pemberitahuan up dan down otomatis ke email, telegram dan sms. Manfaat yang didapat dari penelitian ini yakni dapat menjadi landasan dalam monitoring jaringan kedepannya dan diharapkan dapat menambah wawasan tentang penggunaan the dude mikrotik ini. Sebagai perbandingan penelitian digunakan beberapa jurnal sebagai referensi yang dipaparkan dalam tabel 1 berikut ini:

\section{Tabel 1}

Penelitian Sebelumnya

\begin{tabular}{llllr}
\hline No & Penulis (tahun) & Judul & Hasil & \\
\hline 1 & (Manggau \& Latif, & E-Monitoring Microtic & Berdasarkan & hasil \\
& 2020) & Network uses The Dude in & implementasi & dan \\
& & Musamus University & pengujian & yang \\
\hline
\end{tabular}




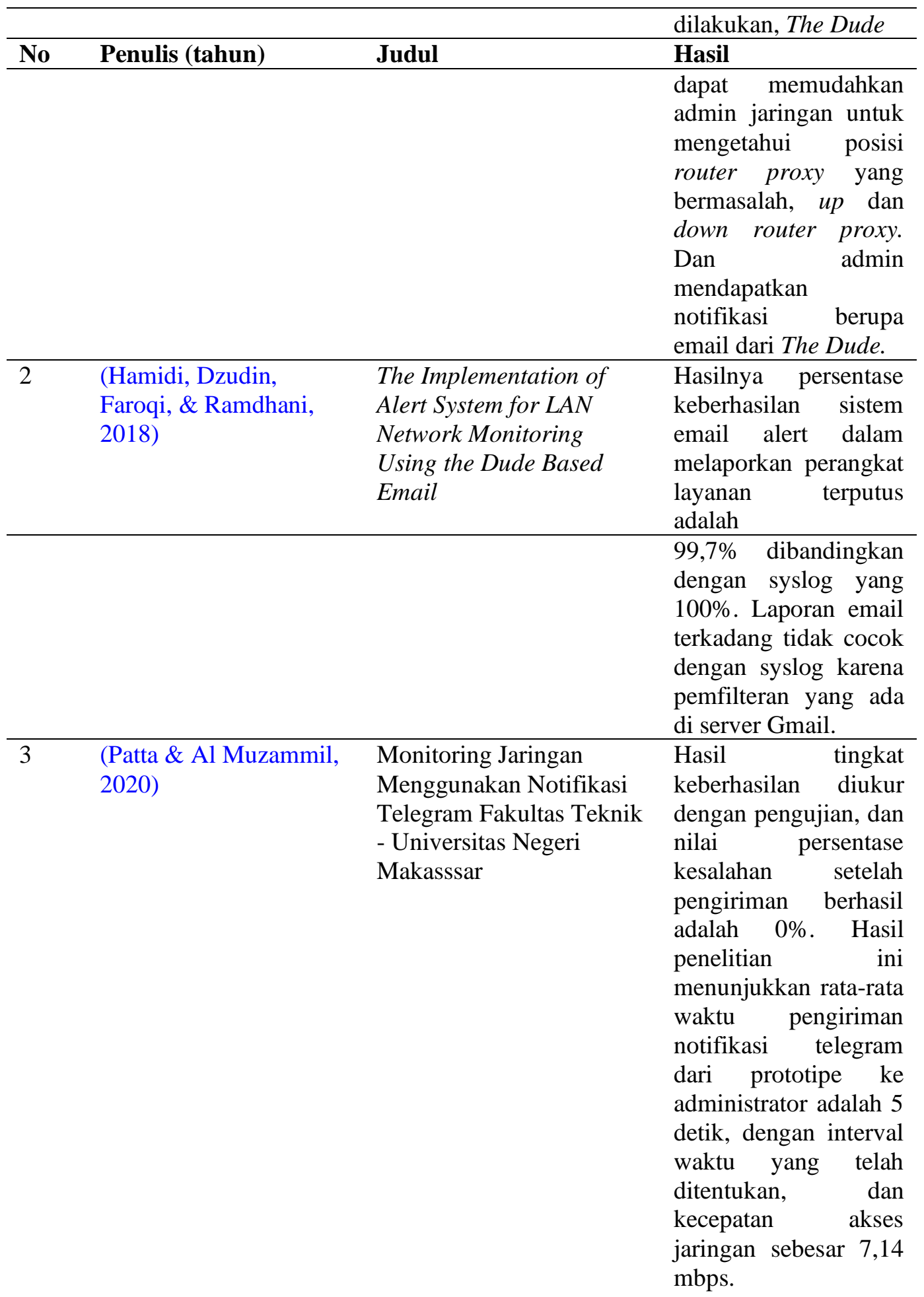

Namun jika kecepatan internet yang digunakan berkurang maka respon notifikasi yang dikirimkan akan berkurang, dan 
Penerapan The Dude Sebagai Sistem Monitoring dengan Notifikasi Otomatis Melalui Email, Telegram dan SMS

\begin{tabular}{|c|c|c|c|}
\hline & & & kekuatan jarak \\
\hline No & Penulis (tahun) & Judul & Hasil \\
\hline & & & 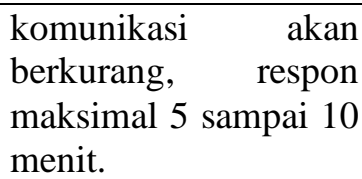 \\
\hline 4 & $\begin{array}{l}\text { (Agung Sulistyo \& Felix } \\
\text { Andreas Sutanto, 2018) }\end{array}$ & $\begin{array}{l}\text { Warning System } \\
\text { Gangguan Jaringan pada } \\
\text { BMKG Semarang Dengan } \\
\text { Telegram Bot }\end{array}$ & $\begin{array}{lr}\text { Ketika ada masalah } \\
\text { dengan } & \text { jaringan, } \\
\text { router Mikrotik dan } \\
\text { bot Telegram dapat } \\
\text { beroperasi } \\
\text { pendeteksi } \\
\text { memberikan } \\
\text { notifikasi dan } \\
\text { teknisi } & \text { kesan } \\
\text { administrator jaringan. }\end{array}$ \\
\hline 5 & (Farida, 2016) & $\begin{array}{l}\text { Implementasi Notifikasi } \\
\text { dengan SMS Pada The } \\
\text { Dude Network Monitoring }\end{array}$ & $\begin{array}{l}\text { Hasil penelitian ini } \\
\text { menunjukkan bahwa } \\
\text { pemantauan lokal dan } \\
\text { jarak jauh dapat } \\
\text { memberikan notifikasi } \\
\text { pesan SMS pada } \\
\text { kasus perangkat } \\
\text { jaringan klien. Waktu } \\
\text { pemungutan suara } \\
\text { default pada the } \\
\text { dude" yang dipantau } \\
\text { secara lokal } \\
\text { memberikan pesan } \\
\text { pemberitahuan pesan } \\
\text { setelah } 2 \text { menit dan } 40 \\
\text { detik setelah } \\
\text { perangkat dianggap } \\
\text { dimatikan, sementara } \\
\text { itu memberikan } \\
\text { pemberitahuan pesan } \\
\text { melalui remote, yaitu } \\
2 \text { menit dan } 40 \text { detik. }\end{array}$ \\
\hline
\end{tabular}

Berdasarkan penelitian sebelumnya diatas maka dapat disimpulkan bahwa terdapat perbedaan penelitian yang akan dilakukan kali ini yaitu:

a. Metode penelitian menggunakan Network Development Life Cycle (NDLC).

b. Tempat penelitian di HE.Net Perumnas Karawang.

c. Sistem notifikasi dirancang untuk email, sms dan telegram.

\section{Metode Penelitian}

Dalam melakukan penelitian ini, metode yang digunakan adalah metode Network Design Life Cycle (NDLC) (Mulyanto \& Prakoso, 2020). 


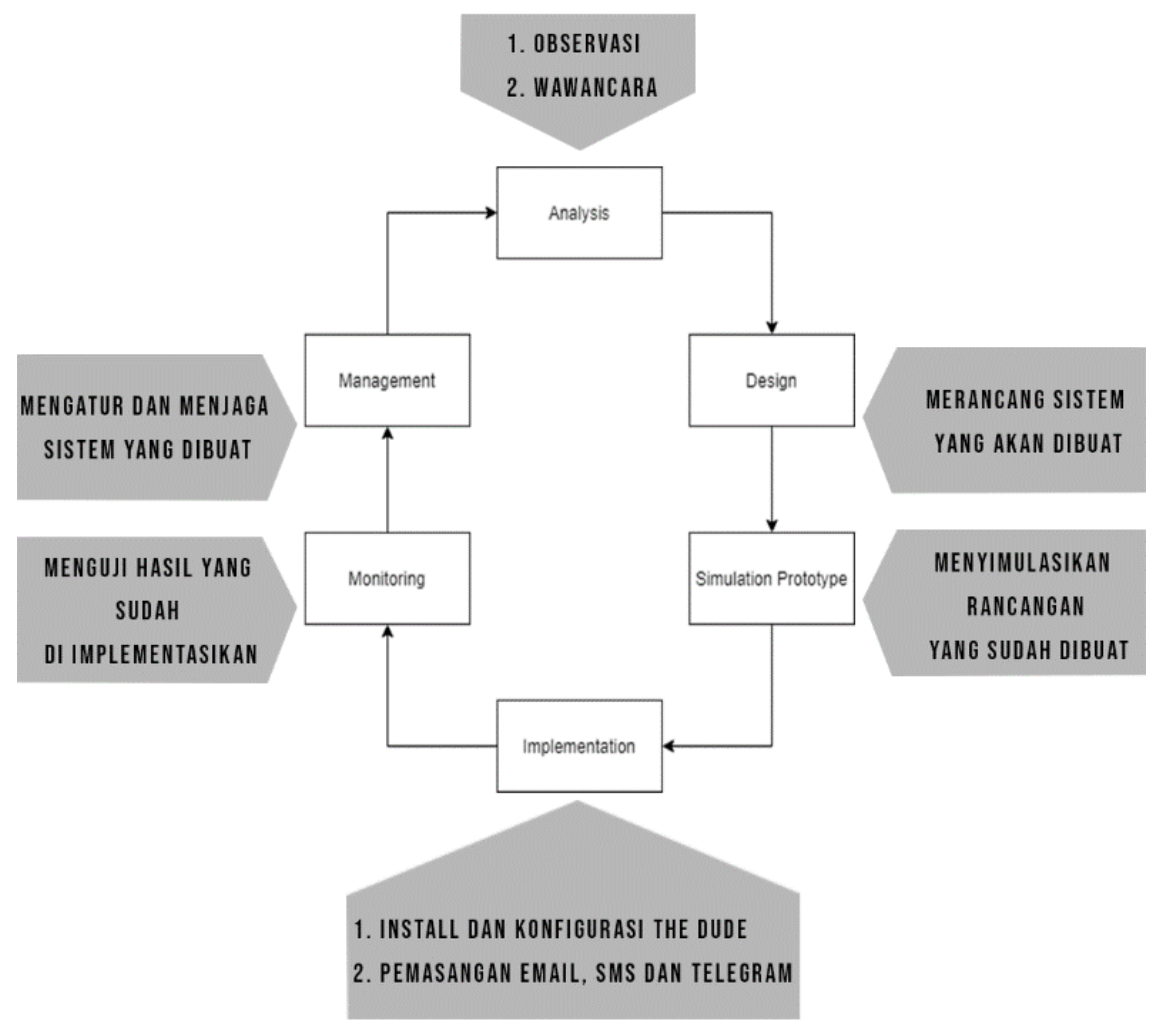

\section{Gambar 1 \\ Tahapan pengembangan NDLC}

Seperti metode pengembangan sistem lainnya, NDLC memiliki beberapa tahapan. Tahapan tersebut adalah (Sanjaya \& Setiyadi, 2019):

A. Pengumpulan Data (Analysis)

Tahapan ini merupakan tahap pertama dari pengembangan jaringan komputer yang mana dilakukan dua kegiatan untuk analisa topologi jaringan yang sudah ada serta mengumpulkan data semua perangkat yang digunakan oleh HE.NET Perumnas Karawang dua kegiatan tersebut yaitu sebagai berikut:

1. Observasi

Mengamati objek secara langsung untuk mengetahui informasi sebagai acuan dalam merancang sistem.

2. Wawancara

Wawancara dilakukan untuk mengumpulkan informasi tentang subjek penelitian dengan bertanya langsung kepada pihak HE.NET Perumnas Karawang.

B. Design

Setelah melakukan tahapan Analysis maka dibuatlah perancangan topologi jaringan usulan, diharapkan dengan diusulkannya topologi jaringan tersebut akan memberikan gambaran seutuhnya mengenai kebutuhan yang ada pada HE.NET Perumnas. Integrasi antara komponen mikrotik, email server, sms server, telegram server dan administrator dapat ditunjukan seperti pada gambar 2. 


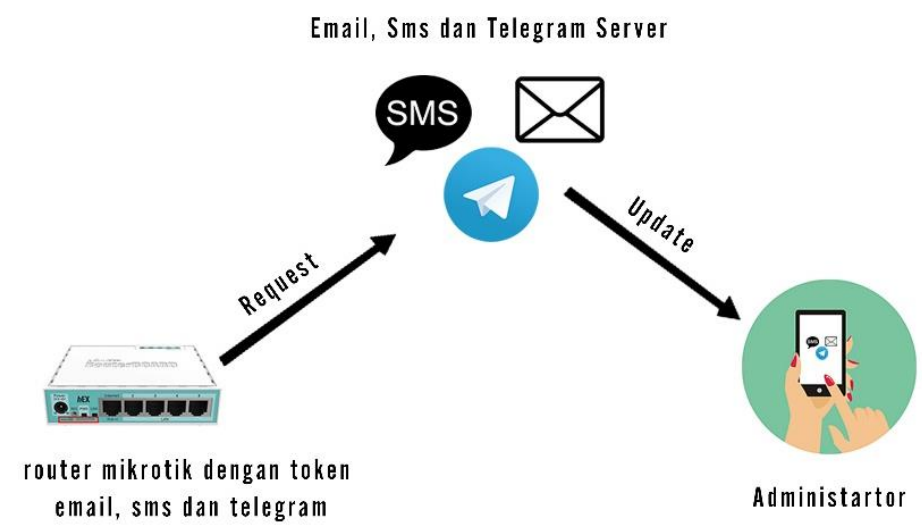

\section{Gambar 2 \\ Integrasi Komponen}

\section{Simulation Prototype}

Pada tahap simulasi ini dilakukan simulasi topologi jaringan usulan yang sudah dirancang untuk HE.NET Perumnas Karawang. Hal ini dilakukan untuk mengetahui performa awal jaringan komputer dan kemudian mendesainnya untuk informasi selanjutnya. Peneliti menggunakan software cisco packet tracert sebagai replika dari sistem yang akan dijalankan pada HE.NET Perumnas Karawang.

D. Implementation

Tahap implementasi ini akan menerapkan seluruh rancangan pada tahapan sebelumnya. Implementasi yang akan dikerjakan oleh peneliti antara lain menginstal dan mengkonfigurasi the dude agar semua perangkat yang digunakan oleh HE.NET Perumnas Karawang dapat terdeteksi kemudian dilanjutkan dengan pemasangan email, sms dan telegram pada the dude (Widodo, 2015).

E. Monitoring

Tahapan monitoring ini dilakukan pengujian agar infrastruktur jaringan yang telah diterapkan atau diimplementasikan pada HE.NET Perumnas Karawang beroperasi dengan baik atau tidak. Jika beroperasi dengan baik, pada saat router mengalami kendala atau down maka the dude akan mengirimkan pesan otomatis melalui email, sms dan telegram.

Data hasil pengujian yang diperoleh kemudian dilakukan perhitungan Persentase Error dengan membandingkan kesalahan relatif yang terjadi dengan nilai aktual kemudian dikalikan dengan total presentase yaitu $100 \%$.

$$
\frac{E}{A} \times 100 \%
$$

Keterangan:

- E adalah banyaknya Error yang terjadi

- A adalah banyaknya kejadian / Nilai Aktual

F. Management

Tahapan manajemen perlu dibuat untuk mengelola dan membuat sistem yang telah dibuat dapat terjaga. Tetapi pada penelitian kali ini, peneliti tidak melakukan 
tahapan manajemen dikarena kan peneliti tidak mempunyai hak akses untuk melakukan penambahan konfigurasi serta memonitor aliran data lalu lintas jaringan maupun melakukan modifikasi (Rochman, Septiana, \& Mulyani, 2019).

\section{Hasil dan Pembahasan}

\section{A. Analysis}

Pada tahap ini peneliti melakukan beberapa kegiatan diantaranya berupa; Analisa masalah, analisa kebutuhan yang digunakan, analisa topologi jaringan dan analisa user. Kegiatan tersebut dilakukan peneliti melalui observasi, wawancara dan studi pustaka dalam hal yang berkaitan dengan jaringan RT/RW-net.

\section{Analisa Masalah}

Berdasarkan dari hasil pengamatan lapangan serta wawancara peneliti dengan administrator jaringan dan beberapa client pada jaringan RT/RW-net bahwa permasalahan yang ada adalah sering mengalami koneksi internet mati secara tiba tiba dan administrator jaringan sulit untuk mengetahui perangkat mana yang bermasalah, ini disebabkan tidak adanya monitoring jaringan yang mampu melakukan monitoring jaringan secara real time.

\section{Analisa Kebutuhan}

Berdasarkan analisis masalah diketahui bahwa diperlukan infrastruktur baik hardware maupun software seperti diuraikan pada tabel 3 berikut ini:

\begin{tabular}{lcl} 
& \multicolumn{2}{c}{ Tabel 2} \\
& Analisa Kebutuhan \\
\hline Hardware & 1. & Mikrotik RB750Gr3 (hEX) \\
& 2. & SD CARD SanDisk 16GB \\
& 3. & Kabel UTP \\
\hline Software & 1. & Dude-install-6.48.1 \\
& 2. & dude-6.48.1-mmips.npk \\
& 3. & Winbox.exe \\
& 4. & Telegram \\
& 5. & Gmail \\
& 6. & SMS API Sender \\
\hline
\end{tabular}

\section{B. Design}

Setelah melakukan analisis, tahap selanjutnya yang dilakukan oleh peneliti melakukan tahapan perancangan (design). Rancangan atau topologi jaringan yang terpasang di HE.NET Perumnas Karawang yang diperoleh setelah melakukan observasi dan wawancara. 


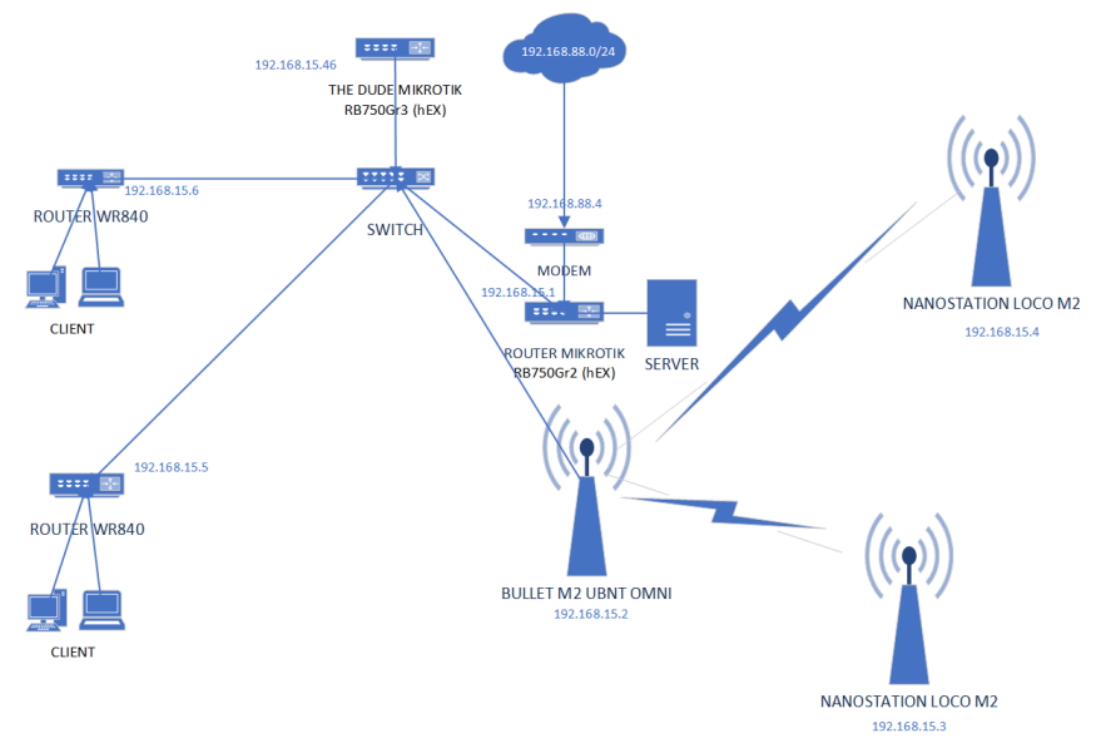

Gambar 3

Topologi Jaringan Rancangan Untuk The Dude

\section{Simulation Prototype}

Pada tahap ini peneliti menggunakan sebuah software Cisco packet Tracer untuk simulasi jaringan usulan yang sudah peneliti rancang pada tahapan sebelumnya. Karena dengan software tersebut peneliti dapat melakukan simulasi jaringan tanpa mengganggu kinerja dari jaringan yang sedang berjalan.

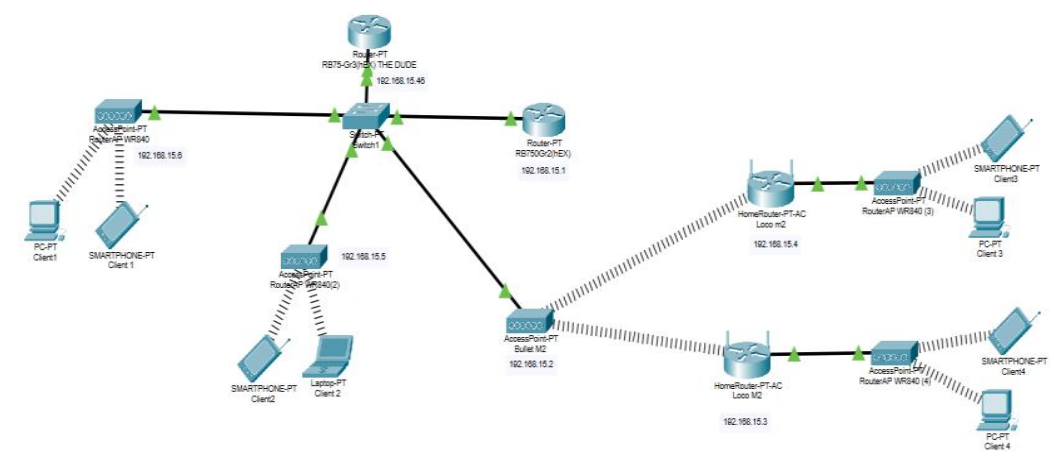

Gambar 4

Simulasi topologi jaringan rancangan the dude

(Jalil, Salim, \& Fattah, 2020)

Pada simulasi yang dilakukan menggunakan software cisco packet tracer diatas peneliti merubah beberapa perangkat seperti Bullet M2 UBNT Omni Hyperlink Server menjadi Acces Point dan Nanostation Loco M2 menjadi Router AP dikarenakan pada software cisco packet tracer tidak ada perangkat yang serupa untuk dijadikan simulasi. 


\section{Implementation}

Setelah tahapan simulasi selesai dilakukan maka langkah selanjutnya adalah tahap implementasi, dimana dilakukan beberapa tahapan untuk melakukan tahapan implementasi ini (Husen, 2020).

\section{Konfigurasi Interface Router Mikrotik}

Tahap dimana membuat dua interface pada mikrotik, yaitu interface lokal dan interface untuk masuk kejaringan HE.Net.

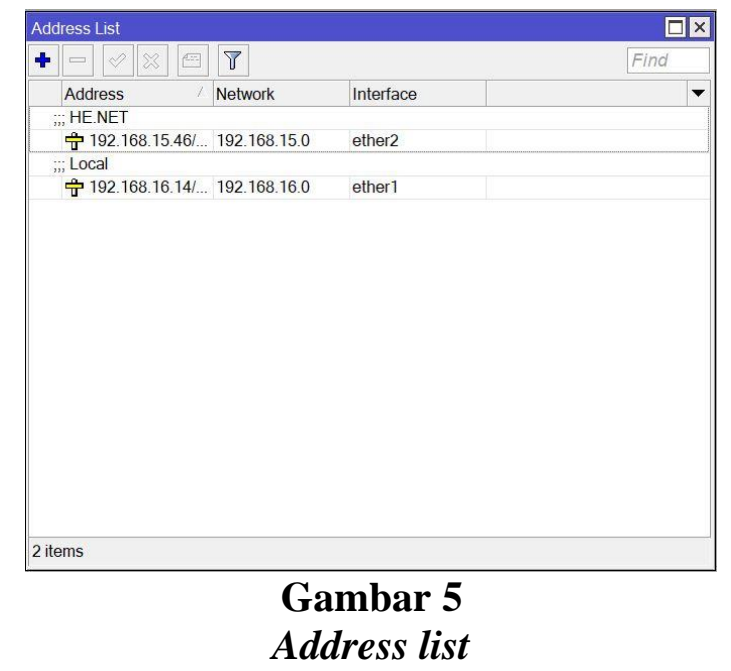

Gambar diatas adalah address list yang sudah di konfigurasi yaitu 192.168.16.14 sebagai ip lokal dan 192.168.15.46 sebagai ip jaringan yang terhubung di HE.Net.

\section{Menambahkan Perangkat Pada Network Map The Dude}

Peneliti tidak melakukan scanning otomatis pada jaringan HE.Net. Peneliti melakukan add device secara manual sesuai dengan topologi yang sudah dipaparkan pada tahapan sebelumnya. Berikut adalah mapping jaringan HE.Net pada the dude: 


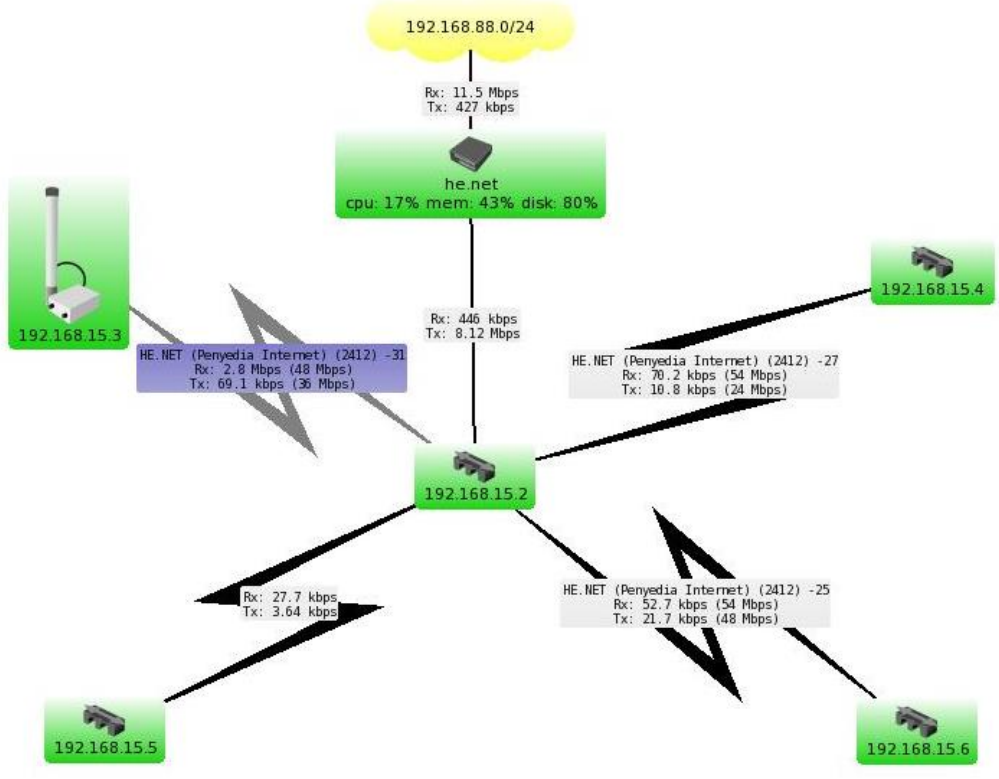

Gambar 6

Mapping Jaringan HE Net di The Dude

3. Konfigurasi sistem notifikasi email, telegram dan sms pada the dude

Peneliti melakukan konfigurasi notifikasi device untuk akses dan penambahan dapat dilihat dengan mengklik tabel atau konten notifikasi, kemudian klik tanda (+) untuk menambahkan settingan notifikasi.

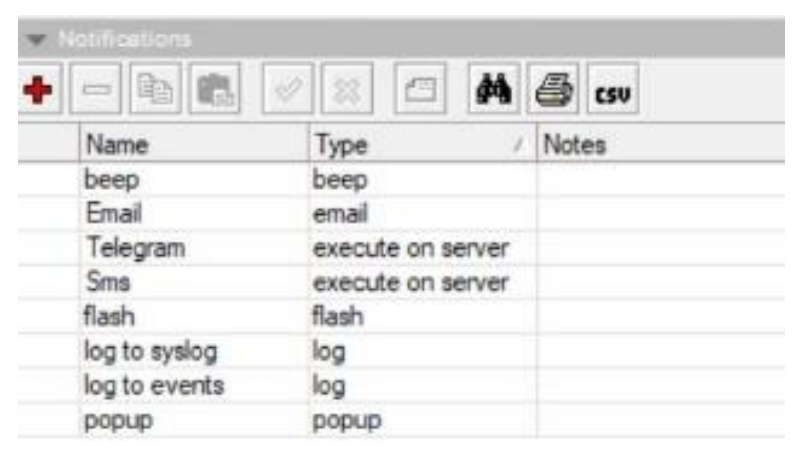

Gambar 7

Tabel atau konten notifikasi the dude

a. Email

Klik tanda (+) kemudian setting seperti dibawah untuk email 


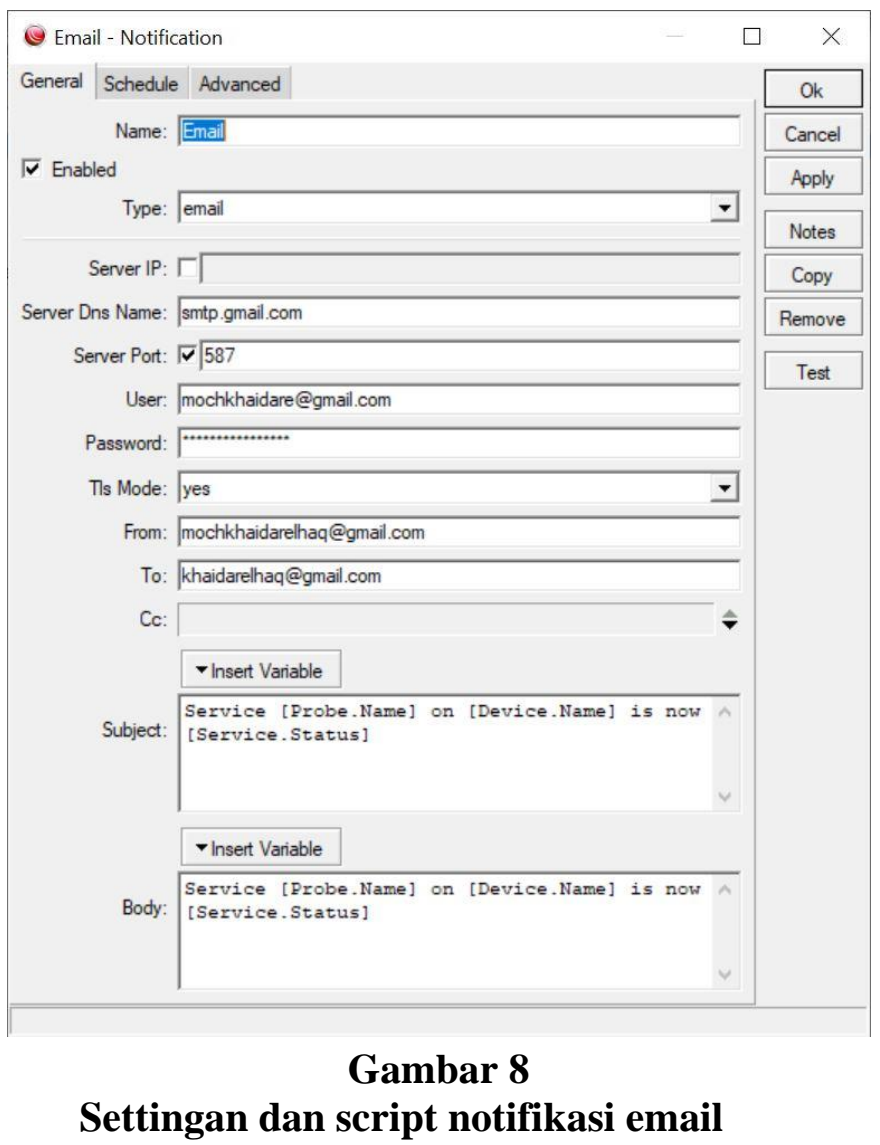

Untuk email peneliti menggunakan email pribadi, dan untuk script email nantinya akan muncul nama service yang diuji (probe.name), nama perangkat (device.name) dan service tersebut berjalan atau tidak (service.status) dimana pada script tersebut akan mengetahui device ketika up dan down.

b. Telegram

Untuk konfigurasi telegram dibutuhkan bot telegram untuk alamat pengiriman notifikasi. Langkah awal pembuatan bot adalah dengan mencari BotFather pada pencarian telegram, kemudian lakukan perintah /start untuk memulai pembuatan bot. Kemudian ketikan perintah /newbot untuk membuat bot baru. Kemudian memberi nama dan username bot seperti bawah ini: 


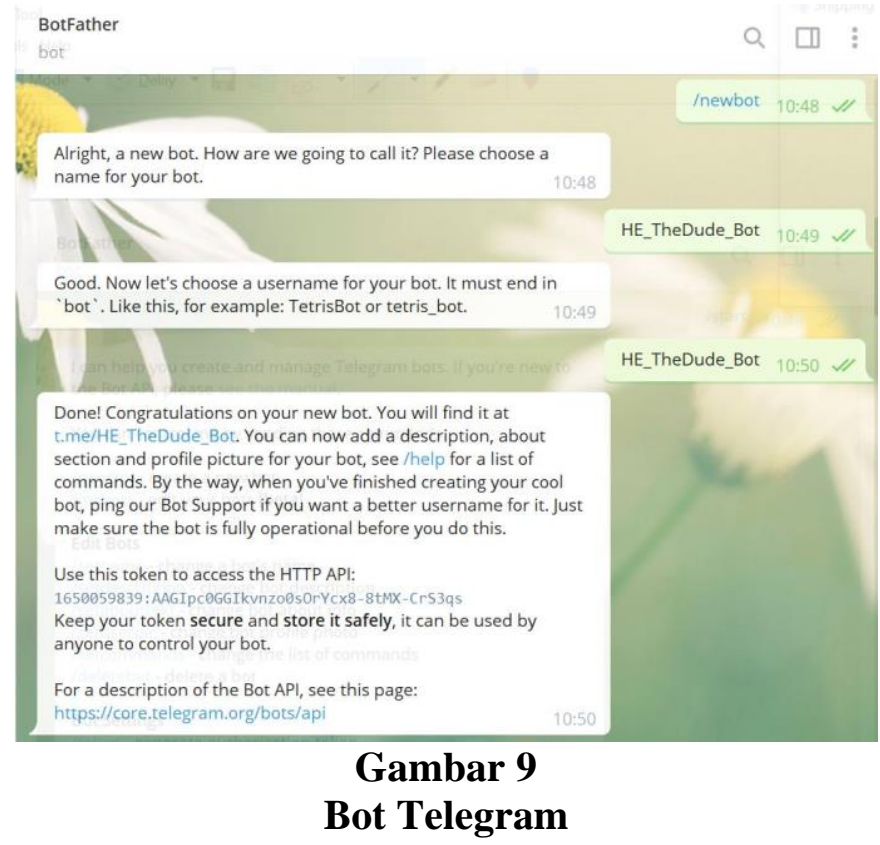

Selanjutnya klik tanda (+) pada tabel atau konten notifikasi di the dude untuk melakukan settingan notifikasi telegram, seperti dibawah ini.

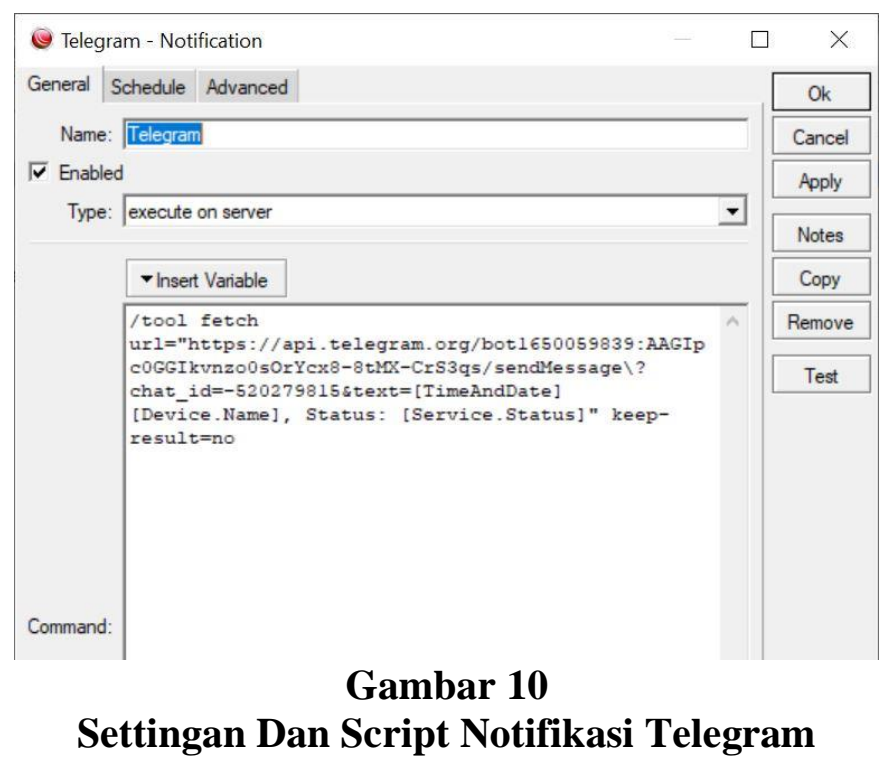

c. SMS

Untuk konfigurasi SMS ini peneliti menggunakan layanan API SMS Sender dari WebSMS. Sebelum melakukan konfigurasi pada the dude, peneliti mengambil API SMS Sender pada WebSMS yang dapat dikunjungi di Web SMS. Selanjutnya akan masuk menu utama WebSMS dan kemudian masuk pada menu Dokumentasi API untuk mendapatkan URL dan API SMS Sender yang akan digunakan pada settingan the dude. 


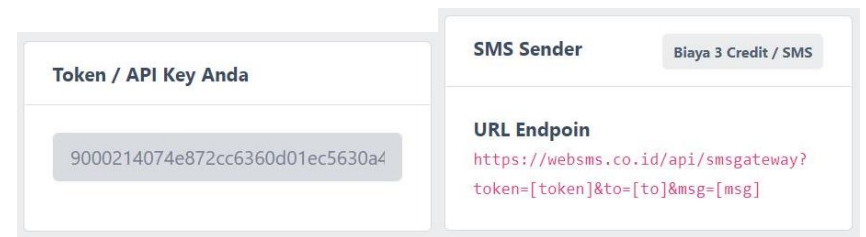

\section{Gambar 11}

\section{Dokumentasi API SMS Sender}

Selanjutnya masuk Kembali pada the dude untuk melakukan konfigurasi notifikasi SMS. Klik tanda (+) pada tabel atau konten notifikasi dan lakukan settingan seperti dibawah ini.

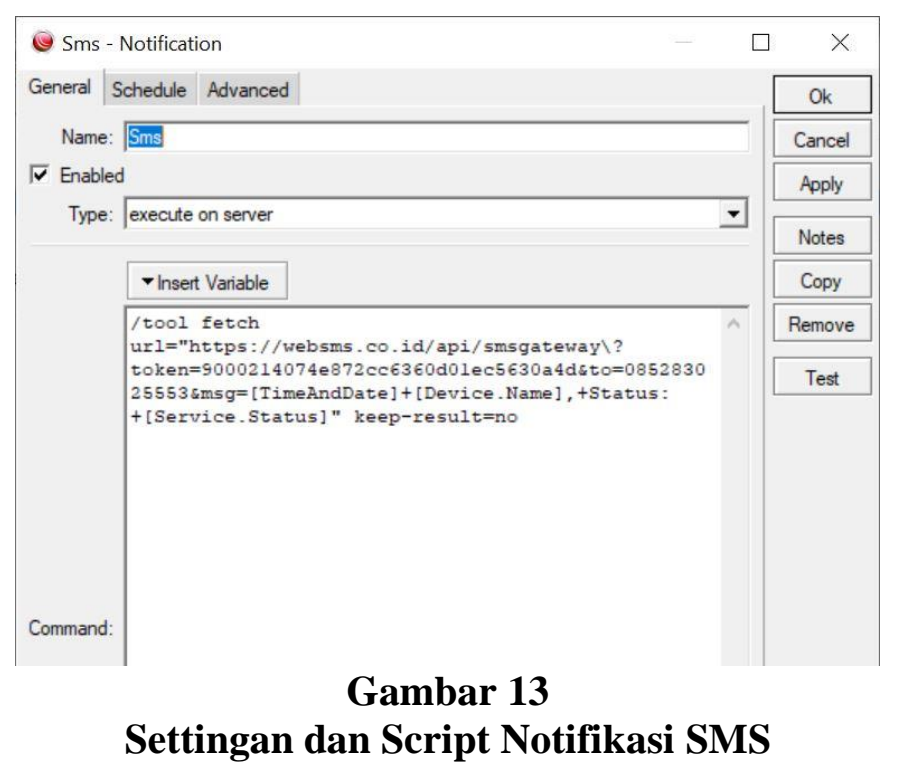

Untuk script notifikasi sms ini menggunakan API SMS Sender dan URL yang didapat pada WebSMS yang ada pada gambar 13 .

\section{E. Monitoring}

Setelah melakukan implementasi, tahapan selanjutnya adalah monitoring. Pada tahap ini peneliti melakukan beberapa pengujian untuk notifikasi email, telegram dan sms. Untuk pengujian dapat dilakukan dengan 2 cara, yaitu dengan mencabut kabel lan pada perangkat yang terhubung ataupun dengan melakukan disable interface pada router mikrotik (Miftah, 2019). 


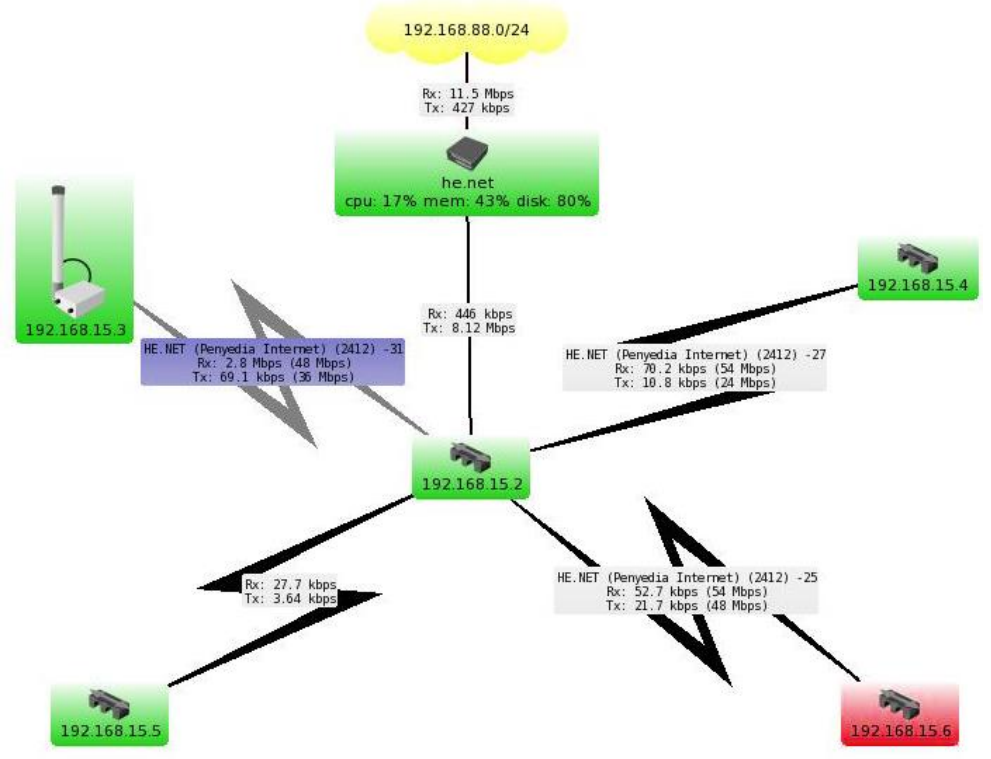

Gambar 14

Contoh Gambar Perangkat yang Sedang Down

\section{a. Pengujian Notifikasi Email}

Peneliti melakukan pengujian dengan mencabut kabel LAN pada perangkat Router WR840 atau pada IP 192.168.15.6 sebanyak 2 kali percobaan, dimana terdapat 4 kali notifikasi masuk yaitu 2 down dan 2 up. Adapun hasil notifikasi dapat dilihat pada gambar 15 .

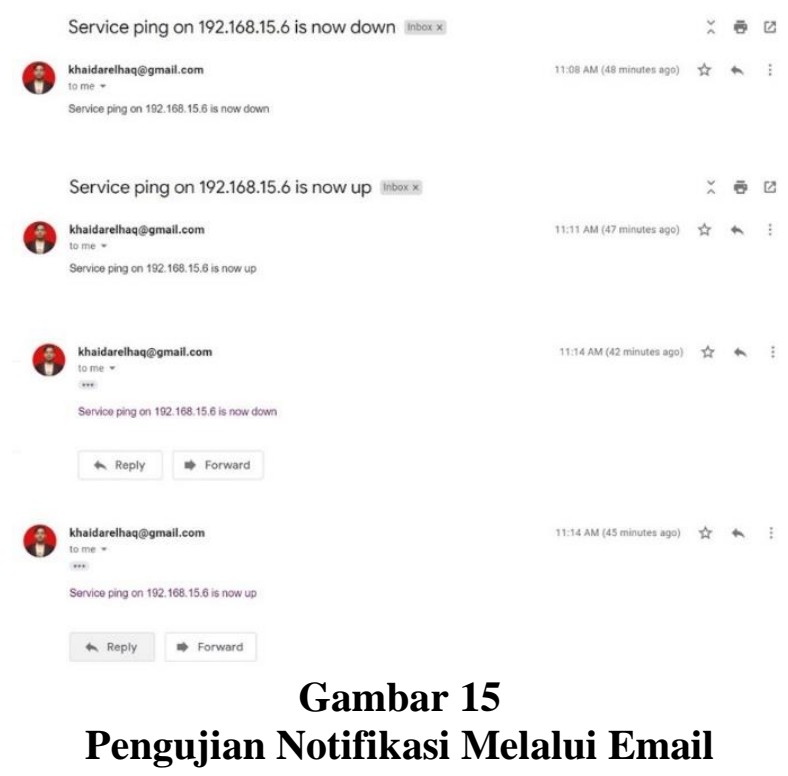

Pengiriman notifikasi terjadi selama selang waktu yang bervariasi, dimana pada pengujian pertama yaitu 12 detik untuk down dan 9 detik untuk notifikasi perangkat up. Sedangkan untuk pengujian kedua selang waktu yang terjadi yaitu 7 detik down dan 7 detik up. 


\section{b. Pengujian Notifikasi Telegram}

Peneliti melakukan pengujian dengan mencabut kabel LAN pada perangkat Router WR840 atau pada IP 192.168.15.6 sebanyak 2 kali percobaan, dimana terdapat 4 kali notifikasi masuk yaitu 2 down dan 2 up. Adapun hasil notifikasi dapat dilihat pada gambar 16 .

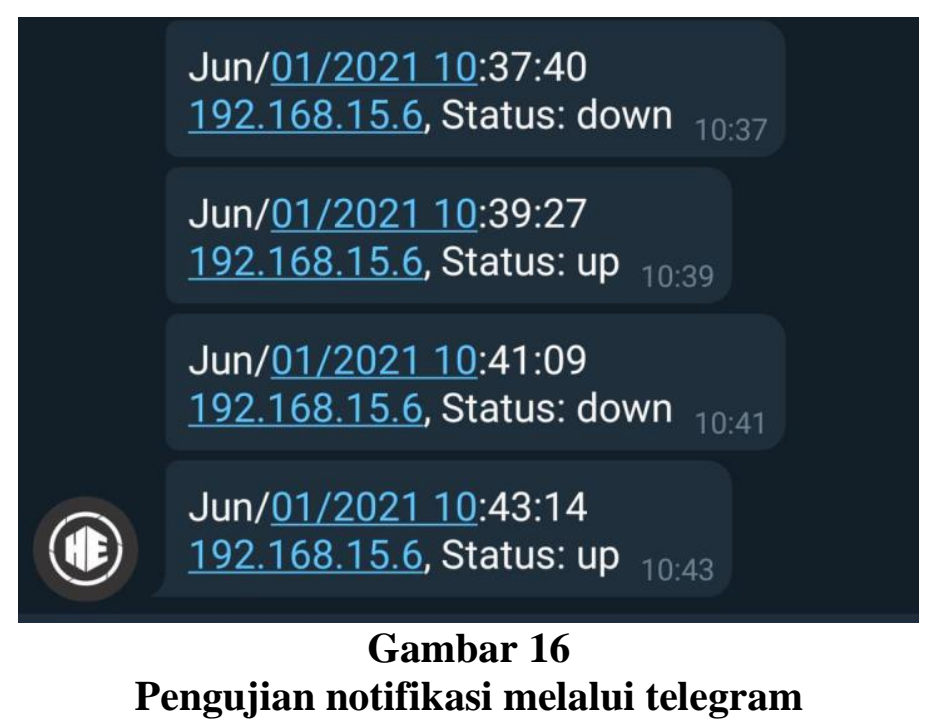

Pada gambar diatas menunjukan bahwa ketika router WR840 atau dengan nama perangkat 192.168.15.6 up dan down the dude berhasil mengirimkan informasi pada telegram. Pengujian pertama notifikasi masuk telegram selang waktu 3 detik untuk perangkat down dan 5 detik untuk perangkat up. Sedangkan untuk pengujian kedua selang waktu yang terjadi yaitu 3 detik up dan 3 detik down.

\section{c. Pengujian Notifikasi SMS}

Peneliti melakukan pengujian dengan mencabut kabel LAN pada perangkat Router WR840 atau pada IP 192.168.15.6 sebanyak 2 kali percobaan, dimana terdapat 4 kali notifikasi masuk yaitu 2 down dan 2 up. Adapun hasil notifikasi dapat dilihat pada gambar 17. 

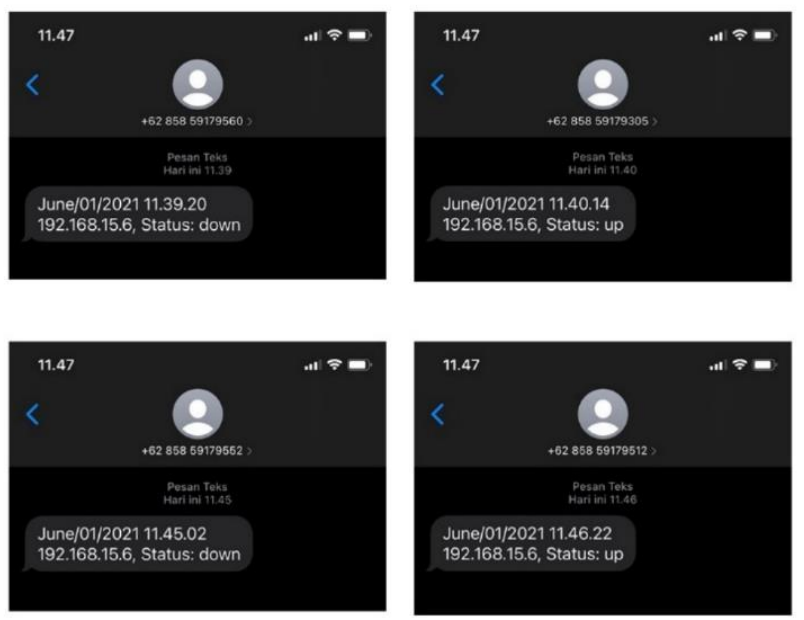

Gambar 17

\section{Pengujian notifikasi melalui SMS}

Pada gambar diatas menunjukan bahwa ketika router WR840 atau dengan nama perangkat 192.168.15.6 up dan down the dude berhasil mengirimkan informasi pada SMS. Pengujian pertama notifikasi masuk SMS selang waktu 10 detik untuk perangkat down dan 13 detik untuk perangkat up. Sedangkan untuk pengujian kedua selang waktu yang terjadi yaitu 11 detik up dan 20 detik down.

\section{d. Perhitungan Kesalahan}

Dengan data yang terdapat pada point-point sebelumnya maka kita dapat menghitung kesalahan untuk membandingkan persentase nilai kesalahan yang terjadi dengan seluruh jumlah kejadian dari email, telegram dan sms.

$$
\frac{E}{A} \times 100 \%
$$

Nilai rata-rata error adalah:

$$
\begin{aligned}
& =\frac{0}{4} \times 100 \% \\
& \% \text { Error }=0 \%
\end{aligned}
$$

\section{e. Menghitung Rata-Rata Pengiriman}

Rumus rata-rata

$$
X=\frac{X 1+X 2+\cdots+X n}{n}
$$

Rata-rata selang waktu pengiriman melalui Email

$=\frac{12+9+7+7}{4}=\frac{35}{4}=8,75$ detik

Rata-rata selang waktu pengiriman melalui Telegram

$=\frac{3+5+3+3}{4}=\frac{14}{4}=3,5$ detik

Rata-rata selang waktu pengiriman melalui SMS

$=\frac{10+13+11+20}{4}=\frac{54}{4}=13,5$ detik 
Berdasarkan hasil pengujian yang telah dilakukan dalam penelitian ini dapat disimpulkan bahwa ketika terjadi perubahan status device, notifikasi dapat terkirim melalui email, telegram dan SMS. Informasi pada ketiga notifikasi tersebut berisi Ip address dan status device, serta waktu dan tanggal perubahan status device yang terkirim sesuai dengan yang ada pada the dude dan mikrotik. Pengujian dilakukan 4 kali, baik pada email, telegram dan sms dengan persentase keberhasilan $100 \%$. Hasil perbandingan antara jumlah kejadian dipresentasekan dengan nilai maksimal presentase sebesar 100\%, maka didapat nilai error $0 \%$ dengan rata rata pengiriman melalui email 8,75 detik, telegram 3,5 detik dan 13,5 detik untuk SMS.

Jika dibandingkan dari ketiga sistem notifikasi tersebut, melalui SMS memiliki kekurangan. Kekurangan tersebut yaitu nomor telepon pengirim notifikasi berbeda-beda dikarenakan masih menggunakan layanan SMS API Sender dan selang waktu pengiriman notifikasi yang delay cukup lama, sehingga cara yang paling efektif adalah notifikasi melalui telegram.

Table 3

Hasil Pengujian

\begin{tabular}{clll}
\hline No & \multicolumn{1}{c}{ Pengujian } & Hasil Yang Diharapkan & Hasil Pengujian \\
\hline 1 & $\begin{array}{l}\text { Monitoring menggunakan } \\
\text { the dude pada jaringan } \\
\text { HE.Net }\end{array}$ & $\begin{array}{l}\text { Menampilkan resource } \\
\text { perangkat yang di monitoring }\end{array}$ & Berhasil \\
\hline 2 & $\begin{array}{l}\text { Pengiriman notifikasi } \\
\text { ketika device down }\end{array}$ & $\begin{array}{l}\text { Menampilkan pesan } \\
\text { notifikasi berisi service } \\
\text { device yang down }\end{array}$ & Berhasil \\
\hline 3 & $\begin{array}{l}\text { Pengiriman notifikasi } \\
\text { ketika device up }\end{array}$ & $\begin{array}{l}\text { Menampilkan pesan } \\
\text { notifikasi berisi service } \\
\text { device yang up }\end{array}$ & Berhasil \\
\hline
\end{tabular}

\section{F. Management}

Tahapan selanjutnya adalahan tahap manajemen, dimana peneliti tidak melakukan tahapan ini. Dikarenakan pada tahap ini seorang administrator jaringan mempunyai hak akses penuh dalam menerapkan kebijakan keamanan, melakukan penambahan, memonitor aliran data pada lalu lintas jaringan secara rutin maupun melakukan modifikasi baik pada struktur jaringan ataupun sistem yang ada.

\section{Kesimpulan}

Berdasarkan hasil penelitian yang telah dilakukan, maka dapat disimpulkan bahwa: 1). HE. Net Sering mengalami kendala koneksi internet mati secara tiba-tiba dan administrator jaringan sulit untuk mengetahui perangkat mana yang bermasalah, ini disebabkan tidak adanya monitoring jaringan yang mampu melakukan secara real time. Sehingga the dude dapat menjadi solusi untuk membantu administrator jaringan untuk mengetahui status sistem jaringan yang berjalan seperti traffic, status device serta 
jumlah device yang terhubung pada jaringan. Dengan menggunakan sistem notifikasi berupa email, telegram dan SMS sangat membantu administrator jaringan untuk mendapatkan update status device tanpa harus memeriksa secara real time, sehingga dapat memberikan efisiensi kerja bagi administrator jaringan. 2). The dude sebagai sistem monitoring dan manajemen perangkat pada pengiriman pesan otomatis melalui email, telegram dan sms dapat diterapkan dengan menggunakan Bot Telegram Grup dan layanan SMS API Sender. 


\section{BIBLIOGRAFI}

Agung Sulistyo, \& Felix Andreas Sutanto. (2018). Warning System Gangguan Konektivitas Jaringan Pada Bmkg Semarang Dengan Telegram Bot. Prosiding Sintak 2018, ISBN: 978-, 126-133. Google Scholar

Farida, Triana. (2016). Implementasi Notifikasi Dengan Sms Pada the Dude Network Monitoring (Implementasi Notifikasi Dengan Sms Pada the Dude Network Monitoring). Jurnal Manajemen Informatika, 5(2), 42-49. Google Scholar

Hamidi, E. A. Zaki, Dzudin, L. S., Faroqi, Adam, \& Ramdhani, Muhammad Ali. (2018). The Implementation of Alert System for LAN Network Monitoring Using the Dude Based Email. IOP Conference Series: Materials Science and Engineering, 288(1), 12054. IOP Publishing. Google Scholar

Husen, Saddam. (2020). Implementasi Api Librenms Pada Sistem Monitoring Server. Studi Kasus: Kampus ITB Stikom Bali. Google Scholar

Idrus, Ali. (2016). Sistem Monitoring Jaringan PT. Exhibition Network Indonesia DenganThe Dude Berbasis Mikrotik. Informatics For Educators And Professional: Journal of Informatics, 1(1), 84-93. Google Scholar

Jalil, Muhammad, Salim, Yulita, \& Fattah, Farniwati. (2020). Simulasi Jaringan Lokal Menggunakan Sistem Kerja The Dude. Buletin Sistem Informasi Dan Teknologi Islam, 1(1), 5-10. Google Scholar

Manggau, Fransiskus X., \& Latif, Agustan. (2020). E-Monitoring Microtic Network uses The Dude in Musamus University. Journal of Physics: Conference Series, 1569(2), 22024. IOP Publishing. Google Scholar

Miftah, Zaeni. (2019). Penerapan Sistem Monitoring Jaringan Dengan Protokol SNMP Pada Router Mikrotik dan Aplikasi Dude Studi Kasus Stikom CKI. Faktor Exacta, 12(1), 58-66. https://doi.org/10.30998/faktorexacta.v12i1.3481

Mulyanto, Yudi, \& Prakoso, Satrio Budi. (2020). Rancang Bangun Jaringan Komputer Menggunakan Sistem Manajemen Omada Controller Pada Inspektorat Kabupaten Sumbawadengan Metode Network Development Life Cycle (NDLC): Rancang Bangun Jaringan Komputer Menggunakan Sistem Manajemen Omada Controller Pada Inspektorat Kabupaten Sumbawadengan Metode Network Development Life Cycle (NDLC). Jurnal Informatika Teknologi Dan Sains, 2(4), 223-233. Google Scholar

Patta, Abd Rahman, \& Al Muzammil, Khalif. (2020). Monitoring Jaringan Menggunakan Notifikasi Telegram Fakultas Teknik-Universitas Negeri Makasssar. Seminar Nasional LP2M UNM. Google Scholar

Rinaldo, Rico. (2016). Implementasi Sistem Monitoring Jaringan Menggunakan Mikrotik Router OS di Universitas Islam Batik Surakarta. Emitor: Jurnal Teknik 
Penerapan The Dude Sebagai Sistem Monitoring dengan Notifikasi Otomatis Melalui Email, Telegram dan SMS

Elektro, 16(2), 56-63. Google Scholar

Rochman, Saepul, Septiana, Yosep, \& Mulyani, Asri. (2019). Perancangan Arsitektur Jaringan Untuk Sekolah Menengah Kejuruan Dengan Menerapkan Konsep The Dude Server. Jurnal Algoritma, 16(2), 130-138. Google Scholar

Sanjaya, Tony, \& Setiyadi, Didik. (2019). Network Development Life Cycle (NDLC) Dalam Perancangan Jaringan Komputer Pada Rumah Shalom Mahanaim. Jurnal Mahasiswa Bina Insani, 4(1), 1-10. Google Scholar

Sutarti, Sutarti, \& Alfiyansyah, Alif. (2017). Analisis dan Implementasi Sistem Monitoring Koneksi Internet Menggunakan The Dude Di STIKOM Al Khairiyah. JSiI (Jurnal Sistem Informasi), 4. Google Scholar

Widodo, Adi. (2015). Implementasi Monitoring Jaringan Komputer Menggunakan Dude. Teknologi Informasi, 11, 1-10. Google Scholar

\section{Copyright holder:}

Moch Khaidar Elhaq, Arip Solehudin, Didi Juardi (2021)

First publication right:

Syntax Literate: Jurnal Ilmiah Indonesia

This article is licensed under: 